\title{
New Trends in Surgical Stabilization of Thoraco-Lumbar Spinal Fractures with Emphasis for Sublaminar Wiring $\star$
}

\author{
Behrooz A. Akbarnia, M.D. ${ }^{1}$, James P. Fogarty, M.D. ${ }^{1}$ and Kenneth R. \\ Smith, Jr., M.D. ${ }^{2}$ \\ ${ }^{1}$ Department of Orthopedic Surgery. ${ }^{2}$ Section of Neurological Surgery, Depart- \\ ment of Surgery, St Louis University Medical Center, 1465 South Grand Boulevard, \\ St Louis, Missouri 63104, U.S.A.
}

\section{Summary}

Sixteen patients with unstable thoracic and lumbar spinal fractures and fracturedislocations were treated surgically by contoured Harrington instrumentation and spinal fusion. Instrumentation was supplemented by sublaminar wires above and below the level of injury. Complications occurred in ten patients. All had solid fusion at follow-up. No loss of reduction occurred. Fourteen patients had a fewett hyperextension brace post-operatively, and two had no immobilization.

Key words: Spinal fractures; Harrington instrumentation; Spinal cord injury; Sublaminar wiring; Segmental instrumentation.

\section{Introduction}

The advantages of surgical stabilization versus non-operative treatment of spinal fractures are still controversial (Getzbein et al., 1982; Lewis \& McKibbin, 1974; Malcom et al., 1981; Osebold et al., 1981). Since early reports on the use of Harrington distraction rods in the treatment of spinal fractures and fracturedislocations (Dickson et al., 1973), there has been a general acceptance of this technique when stabilization is required. Most of the clinical evaluations of patients treated by this method have been favourable (Bradford et al., 1977; Flesh et al., 1977; Jacobs et al., 1980). There are a few reports, however, of a high rate of complication associated with this technique (Getzbein et al., 1982). Luque has introduced the concept of segmental fixation as a more rigid method of instrumentation for the treatment of spinal disorders (Luque et al., 1982). Traditional Luque instrumentation or a combination of Harrington distraction rods with sublaminar wires have been used in the stabilization of spinal fractures (Gaines et al., 1983; Luque et al., 1982). The purpose of this paper is to evaluate the results of spinal fusion and instrumentation in a group of patients when

$\star$ Read at the Annual Meeting of International Medical Society of Paraplegia, May 1983, Stoke Mandeville Hospital, Aylesbury, England. 
contoured Harrington distraction rods, supplemented by sublaminar wires were used.

\section{Methods}

There were 16 patients, 12 males and four females, with an average age of 30 years in this series. These cases consisted of approximately 50 per cent of the operations performed at St Louis University Medical Center for spinal fractures, in the period covered by this study (September 1981-December 1982). All of the medical records and roentgenograms of these patients were studied and the patients were examined at follow-up.

The cause of the injuries are listed in Table 1. There were 16 associated injuries in 11 patients. These included seven chest injuries, five limb injuries and four head injuries. Five patients had thoracic, eight thoracolumbar and three lumbar fractures. Fractures and fracture-dislocations were classified using the three-column concept of Denis (Denis, 1982) (Table 2). Displacement of the vertebrae was graded from 0 through 4 according to the percent of forward or lateral displacement seen in roentgenograms (e.g., 0 for no displacement and I for $0-25 \%$ ). There was no displacement in six patients. Six patients had Grade I, 3 were Grade II and 1 had Grade IV displacement. The angular deformity measured from one vertebra above to one vertebra below the fracture site on lateral roentgenogram and averaged 21 degrees pre-operatively. All patients had computerized axial tomography as part of their work-up, pre- and postoperatively, to evaluate the integrity of the spinal canal and other parts of the vertebra.

Table 1 Cause of injury

\begin{tabular}{lr}
\hline Motor Vehicle Accident & 10 \\
Fall & 4 \\
Crush & 2 \\
\hline
\end{tabular}

Table 2 Type of fractures

\begin{tabular}{ll}
\hline Burst & 7 \\
Fracture-Dislocations & 4 \\
Compression & 2 \\
Seat Belt Type & 3 \\
\hline
\end{tabular}

Neurologically, using the Frankel classification, there were 4 Frankel A, 2 Frankel B, 1 Frankel D and the remaining nine patients were neurologically intact. Indications for surgery was acute or chronic instability or need for decompression when there was neurological deterioration.

Surgical technique consisted of dual Harrington distraction instrumentation using contoured rods (square end for lumbar and thoracolumbar fractures). Usually, three vertebrae above and three vertebrae below the fracture were instrumented. In the thoracolumbar spine, rods were so contoured as to give a three-point fixation supporting the fractured vertebra along with one vertebra above and one vertebra below in the middle portion of the rod. In the thoracic 
area the amount of kyphosis was adjusted to give the same type of support. The spine was fused through the length of the rod in all patients. This was felt to be necessary so the instruments along with the wires need not be removed later on. Bilateral sublaminar wires were usually used two levels above and two levels below the level of injury, using the intact laminae. These wires were either 16 gauge stainless steel single wires or 18 gauge double wires. In two patients, a Harrington compression rod was combined with the distraction rod. Of five patients who had laminectomies at the time of fusion, one patient had complete paraplegia, two were neurologically intact and two had incomplete paraplegia. The average blood loss was 1340 millilitres.

Post-operatively, no patient had a body cast applied. Fourteen patients had a Jewett hyperextension brace and two patients had no immobilization.

\section{Results}

All patients were followed for 1-2 years with an average of $1 \frac{1}{2}$ years. Satisfactory reduction was achieved in all patients (all had 0 displacement and almost no angulation). Fusion was present at an average of 7 months. The average time from surgery to discharge from the acute care facility was 20 days.

Neurologically, all of the intact patients remained intact and all complete injuries remained complete. Two incomplete injuries improved (Table 3).

In seven patients with burst fractures of the spine, where there was evidence of spinal canal compromise by free bone fragments, pre- and post-operative CT scans were performed. The canal compromise graded I to IV (I for $0-25 \%$ and IV for $75-100 \%$, etc.). One patient was Frankel D and the remaining patients

Table 3 Neurological status

\begin{tabular}{cc}
\hline Pre-op & Post-op \\
\hline $4 \mathrm{~A}$ & $4 \mathrm{~A}$ \\
$2 \mathrm{~B}$ & $2 \mathrm{D}$ \\
$1 \mathrm{D}$ & $1 \mathrm{D}$ \\
\hline
\end{tabular}

Table 4 Spinal canal compromise demonstrated by CT Scans in burst fractures

\begin{tabular}{rccccc}
\hline Patient & Level & $\begin{array}{c}\text { Pre-op } \\
\text { Neurological } \\
\text { Status }\end{array}$ & $\begin{array}{c}\text { Post-op } \\
\text { Neurological } \\
\text { Status }\end{array}$ & $\begin{array}{c}\text { Pre-op } \\
\text { Compromise }\end{array}$ & $\begin{array}{c}\text { Post-op } \\
\text { Compromise }\end{array}$ \\
\hline R.D. & L1 & I & I & III & III \\
M.H. & L2 & I & I & II & I \\
D.D. & L1 & D & D & III & II \\
D.L. & L1 & I & I & II & II \\
L.C. & L1 & I & I & II & I \\
P.K. & L4 & I & I & I & I \\
A.M. & L1 & I & I & & II \\
\hline I $=0-25 \%$ & I $=$ Intact & & & & \\
II $=25-50 \%$ & & & & & \\
III $=50-75 \%$ & & & & &
\end{tabular}


Table 5 Complications

\begin{tabular}{ll}
\hline Urinary Tract Infections & 6 \\
Instrumentational Problems & 4 \\
Deep Wound Infection & 2 \\
Pseudarthrosis & 1 \\
Pneumonia \& Respiratory Distress & 2 \\
Deep Venous Thrombosis & 1 \\
DIC & 1 \\
\hline
\end{tabular}

were neurologically intact. All remained unchanged post-operatively. The post operation CT scan showed no change in four and one grade improved in the remaining three patients (Table 4 ).

Complications occurred in ten patients (Table 5). From four patients with instrumentational problems, one required re-operation and adjustment. Two patients with deep wound infection were treated with antibiotics and wound care in one patient, and antibiotics and suction irrigation in another and both healed uneventfully. One patient had pseudarthrosis and was regrafted. At follow-up, all patients demonstrated solid fusion (Fig. 1A-E).

\section{Discussion}

The rôle of surgical stabilization of fractures and fracture-dislocations of the spine is still controversial. Harrington instrumentation has received wide acceptance as the method of choice when internal fixation is carried out. The use of straight rods prevents complete reduction of angular deformity and causes collapse especially in burst fractures (Getzbein et al., 1982). Lordodic bend provides a three point fixation and therefore, better correction of the deformity (Jacobs et al., 1980). All of the fractures were satisfactorily corrected and maintained. Contoured Harrington instrumentation in burst fractures, however, did not significantly reduce the bone fragments, protruding into the spinal canal (Table 4).

Sublaminar wires only add to the stability of the system and do not necessarily improve the reduction. The advantage of sublaminar wires seems to be less need for external immobilization, especially a body cast. This is an advantage in paralysed patients and/or patients who are not reliable. The addition of sublaminar wires in neurologically intact patients may add to the stability, but nevertheless, carries an increased risk of neurological damage. Furthermore, fusion is necessary through the length of the instrumentation. This is a disadvantage when the instrumentation is extended into the lumbar spine, leaving less mobile vertebral segments.

Therefore, we do not recommend sublaminar wiring in neurologically intact patients unless there are problems with application of the cast (e.g., severe obesity or non-compliance). The traditional Luque instrumentation does not provide distraction and does not withstand axial loading (Gaines et al., 1983). This may cause collapse of the vertebra, especially in burst fractures. However, this may not be so important in patients with complete cord injury. The rectangular Luque rods may overcome this deficiency and give better support in axial loading and warrants further investigation. Fractures associated with incomplete neuro- 

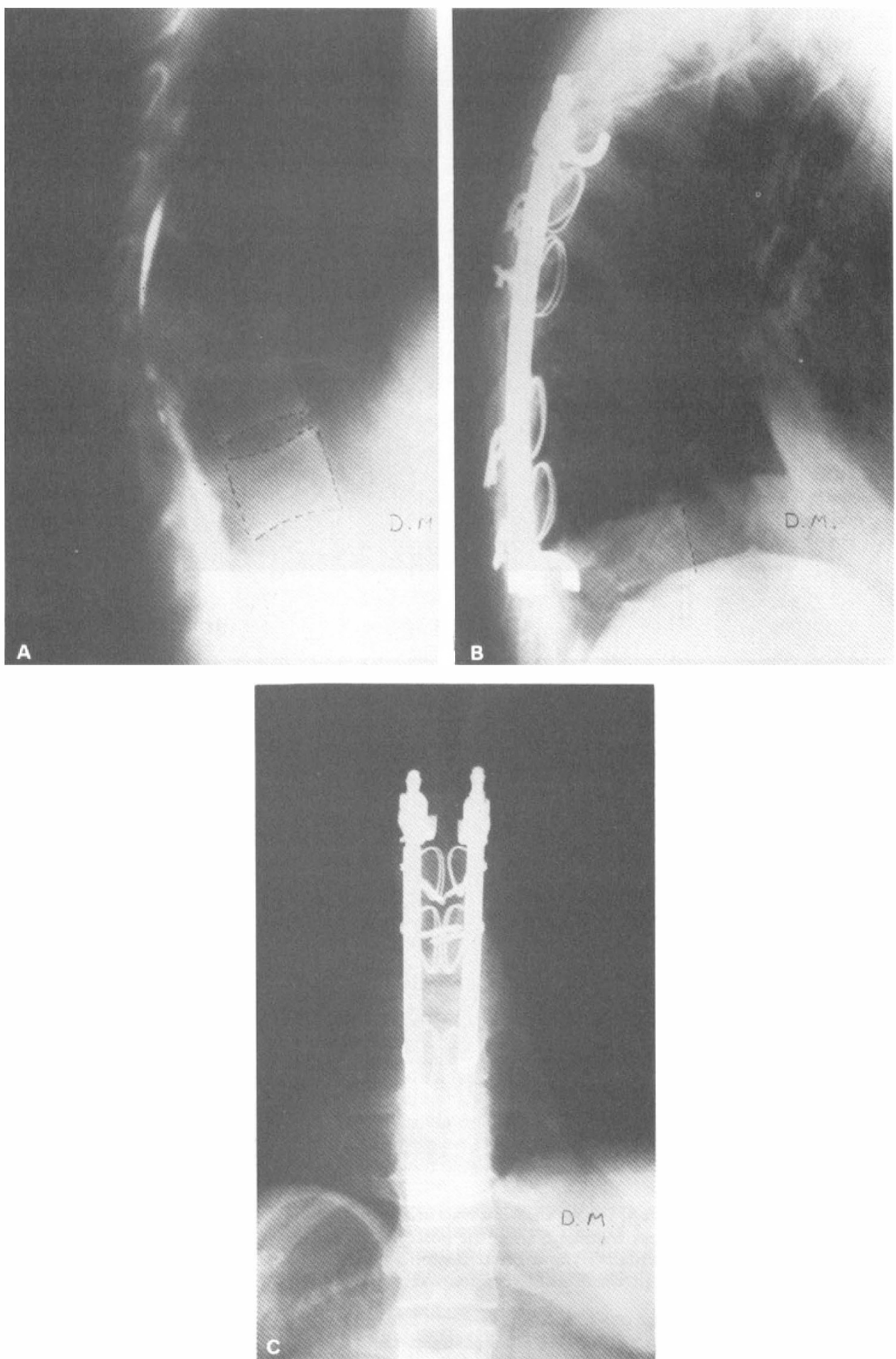

Figure 1. D.M., an 18-year-old female with a T8 complete paraplegia caused by a motor vehicle accident. (A) A lateral roentgenogram of the spine showing a burst fracture of $\mathrm{T} 8$ with fragments protruding into the spinal canal. (B) A lateral roentgenogram after Harrington instrumentation and sublaminar wiring shows normal alignment of the thoracic spine. (C) Anteroposterior roentgenogram after surgery. 

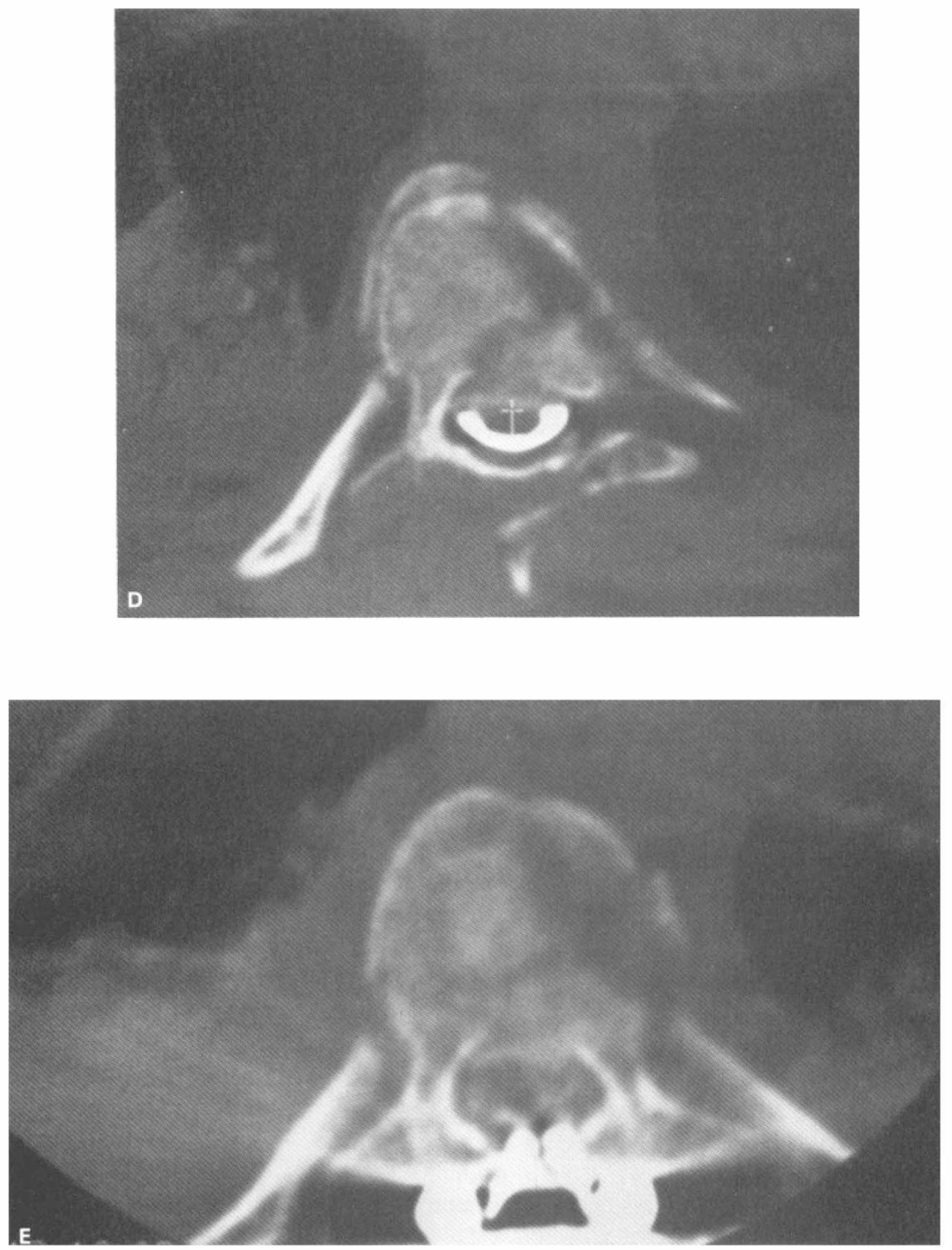

Figure 1. (D) Preoperative CT scan showing fracture of the vertebral body as well as posterior arch. Note the free fragment, from the posterior aspect of the vertebral body, that protrudes into the spinal canal. (E) Immediate postoperative CT scan showing partial reduction of the fragment. Note the presence of Harrington rods have not obscured the details of the image. 
logical deficit may have better results with primary anterior decompression, since removal of fragments anterior to the spinal cord is difficult from a posterior or posterolateral approach.

\section{Conclusion}

Posterior spine fusion and Harrington instrumentation supplemented by sublaminar wiring was used in 16 patients. Best correction may be obtained by using the contoured Harrington distraction rods. Addition of sublaminar wires only adds to the stability of the spine and alleviates the need for a body cast. This technique is not indicated when short fusion is desired, especially in neurologically intact patients with thoracolumbar or lumbar fractures.

\section{Résumé}

On a traité chirurgiquement seize personnes qui souffraient de la fracture soit de la fracture-luxation instable de l'épine thoracique ou lombaire au moyen de l'instrumentation Harrington à contours et de la fusion épinière. On a supplémenté l'instrumentation par des fils subliminaires au-dessous et au-dessous du niveau de la blessure. Des complications ont eu lieu chez dix souffrants. A l'étude ultérieure ils avaient tous une fusion solide. Aucune perte de réduction n'a eu lieu. Quatorze souffrants ont eu une armature d'hyperextension Jewett pendant la période post-opérative, et deux n'ont pas eu d'immobilisation.

\section{Zusammenfassung}

Man hat sechzehn Pazienten mit instabilem Brustwirbel-bzw. Lendenwirbelbruch bzw. BruchLuxation chirurgisch durch konturformige Harrington-Instrumentation und Rückengratfusion behandelt. Man hat die Instrumentation mit unterlaminaren Drähten oberhalb und unterhalb der Verletzungslage ergänzt. Komplikationen sind bei zehn Pazienten vorgekommen. Alle hatten feste Fusion an der Nachbeobachtung. Kein Reduktionsverlust ist vorgekommen. Vierzehn Pazienten hatten eine Jewett-Überdehnungsstütze während der Nachoperationsperiode, und zwei haben keine Immobilisierung gehabt.

\section{References}

Bradford DS, Akbarnia BA, Winter RB, Seljeskog EL 1977 Surgical stablization of fracture and fracture-dislocations of the thoracic spine. Spine 2:185-196.

DENIS F 1982 Updated classification of thoracolumbar fractures. Orthopaedic Transactions 6:8.

Dickson JH, HARRINGTON PR, ERWIN WD 1973 Harrington instrumentation in the fractured, unstable thoracic and lumbar spine. Texas Medicine 69:91-98.

Flesch JR, Leider LL, ERICkson DL, Chou SN, Bradford DS 1977 Harrington instrumentation and spine fusion for unstable fractures and fracture-dislocations of the thoracic and lumbar spine. Journal of Bone and Joint Surgery 59A:143-151.

Gaines RW, Munson G, Satterlee G, Lising A, Betten R 1983 Harrington distraction rods supplemental with sublaminar wires for thoracolumbar fracture dislocation-experimental and clinical investigation. Orthopaedic Transactions 7:15.

GetZBein SD, MacMichael D, Tile M 1982 Harrington instrumentation as a method of fixation in fractures of the spine: a critical analysis of deficiencies. Journal of Bone and Joint Surgery 64Bk:526-529.

JACOBS RR, ASHER MA, SNIDER RK 1980 Thoracolumbar spinal injuries: a comparative study of recumbent and operative treatment in 100 patients. Spine 5:463-477.

LEwIS J, MCKIBBIN B 1974 The treatment of unstable fracture-dislocations of the thoracolumbar spine accompanied by paraplegia. Journal of Bone and Joint Surgery 56B:603612.

LuQue ER, Cassis N, Ramirez-Wiella G 1982 Segmental spinal instrumentation in the treatment of fractures of the thoracolumbar spine. Spine 7:312-317.

Malcom BW, BRAdFord DS, WinTer RB, ChOU SN 1981 Post traumatic kyphosis; a review of forty-eight surgically treated patients. Journal of Bone and Joint Surgery 63A:891-899.

Osebold WR, WeINSTEIN SL, SPRAGUe BL 1981 Thoracolumbar spine fractures; results of treatment. Spine 6:13-34. 